\title{
Aryl hydrocarbon receptor pathway: Role, regulation and intervention in atherosclerosis therapy (Review)
}

\author{
KAIXI ZHU ${ }^{1,2^{*}}$, QINGQI MENG $^{3 *}$, ZHI ZHANG ${ }^{4 *}$, TAO YI $^{1,2}$, YUAN HE $^{2}$, JING ZHENG $^{5}$ and WEI LEI ${ }^{1,2}$ \\ ${ }^{1}$ Cardiovascular Medicine Center; ${ }^{2}$ Laboratory of Cardiovascular Diseases, Affiliated Hospital of Guangdong Medical \\ University, Zhanjiang, Guangdong 524001; ${ }^{3}$ Department of Orthopedics, Guangzhou Red Cross Hospital, Guangzhou, \\ Guangdong 510000; ${ }^{4}$ Department of Vascular, Thyroid and Breast Surgery, Affiliated Hospital of Guangdong Medical College, \\ Zhanjiang, Guangdong 524001, P.R. China; ${ }^{5}$ Department of Obstetrics and Gynecology, \\ University of Wisconsin, Madison, WI 53715, USA
}

Received January 15, 2019; Accepted May 5, 2019

DOI: $10.3892 / \mathrm{mmr} .2019 .10748$

\begin{abstract}
The aryl hydrocarbon receptor (AhR) is a ligand-activated transcription factor originally isolated and characterized as the dioxin or xenobiotic receptor. With the discovery of endogenous ligands and studies of AhR knockout mice, AhR has been found to serve an important role in several biological processes, including immune responses and developmental and pathological regulation. In particular, it has been considered as a new major player in cardiovascular diseases. Recent studies have revealed that the development of atherosclerosis is closely associated with AhR function. However, the roles of the AhR in the pathological development of atherosclerosis and atherosclerosis-associated diseases remain unclear. The current review presents the molecular mechanisms involved in the regulation of AhR expression during inflammation, oxidative stress and lipid
\end{abstract}

Correspondence to: Dr Wei Lei, Laboratory of Cardiovascular Diseases, Affiliated Hospital of Guangdong Medical University, 2 Wenming East Road, Xiashan, Zhanjiang, Guangdong 524001, P.R. China

E-mail: leiwei2006@126.com

*Contributed equally

Abbreviations: AhR, aryl hydrocarbon receptor; PAC, polycyclic aromatic compound; $\mathrm{AHH}$, aryl hydrocarbon hydroxylase; bHLH, basic helix-loop-helix; PAS, Per-Arnt-Sim; VSMCs, vascular smooth muscle cells; ROS, reactive oxygen species; FGF21, fibroblast growth factor 21; CAD, coronary artery disease; T2DM, type 2 diabetes mellitus; CYP1A1, cytochrome $\mathrm{P} 450$, family 1 , subfamily $\mathrm{A}$, polypeptide 1; IL, interleukin; ox-LDL, oxidized low-density lipoprotein; NF- $\mathrm{BB}$, nuclear factor kappa-B; TNF, tumor necrosis factor; VCAM-1, vascular cell adhesion molecule-1; PCBs, planar polychlorinated biphenyls; TCDD, 2,3,7,8-tetrachlorodibenzo-p-dioxin; MMP, matrix metalloproteinase; LXA4, lipoxin A4; HFD, high-fat diet; OR, odds ratio; $\mathrm{CI}$, confidence interval

Key words: AhR, atherosclerosis, inflammation, lipid deposition, endothelial cells deposition. Additionally, the role of the AhR in atherosclerosis and atherosclerosis-associated diseases is reviewed.

\section{Contents}

1. Introduction

2. AhR regulation in atherosclerosis pathogenesis

3. Clinical research about AhR and atherosclerosis-associated diseases

4. Conclusion

\section{Introduction}

The aryl hydrocarbon receptor (AhR) is ligand-dependent and mediates nuclear receptors that react with heterologous substances of phases I and II (Fig. 1). The theory of polycyclic aromatic compound (PAC) metabolic reactions was postulated in the late 1950s (1). The carcinogenic dye 3-methylcholanthrene induces the synthesis of a specific enzyme that detoxifies 3-methylcholanthrene by promoting the synthesis of the liver microsomal enzyme P450, which is an aryl hydrocarbon hydroxylase (AHH) (1). Other carcinogens, including insecticides and phenobarbital, have a similar effect. This increase in synthesis meets the criteria of an adaptive response, as the upregulated enzyme oxidizes the PAH inducer when it is re-exposed within a short timeframe (2-4). Genetic studies have revealed that $\mathrm{AHH}$ is regulated by multiple alleles. These alleles were originally called Ah and used to describe the reaction of aromatic hydrocarbons (5).

The AhR belongs to the basic helix-loop-helix (bHLH) family and has a Per-Arnt-Sim (PAS) domain that binds to a variety of endogenous and exogenous chemicals. It binds specific auxiliary proteins, including heat shock protein 90 and hepatitis B virus $\mathrm{X}$-associated protein, in the cytoplasm of resting state cells $(6,7)$. When the AhR is transferred to the nucleus, it combines with the aryl hydrocarbon receptor nuclear translocator and triggers the transcription of several downstream genes, including cytochrome P450 family 1 subfamily A member 1 (CYP1A1) and cytochrome P450 
family 1 subfamily B member 1 (CYP1B1), resulting in a variety of physiological and toxicological effects (8) (Fig. 2). Aryl hydrocarbon receptors are polymorphic. Known alleles include AhRb-1-3 and AhRd (9). The receptors have different affinities, however; all four proteins are alkaline and contain a bHLH as well as PAS and transactivation domains (10).

The sensitivity of AhR to 2,3,7,8-tetrachlorodibenzo-p-dioxin (TCDD) is species-specific, and its persistence in different organs in vivo varies according to the expression pattern of AhR in the specific organ (11). The AhR is most highly expressed in the human placenta, followed by the lungs, heart, pancreas and liver. Its lowest expression levels are in the kidney, brain and skeletal muscle (9). The AhR is transcribed from highly conserved sequences and plays a regulatory role in system development and physiological processes of different organs. Therefore, its expression is of great importance. The AhR is activated by the high-affinity exogenous ligands HAH and PAH as well as low-affinity endogenous ligands such as arachidonic acid, pyrene, and tryptophan and flavonoid derivatives (12-14). The endogenous ligands activate the AhR to participate in the regulation of cardiac functions, vascular development and blood pressure (15-19). In addition, the AhR signaling pathway senses changes in the circadian rhythm, oxygen tension and redox potential to regulate neural development and vacularization (20). For example, exposure to polycyclic aromatic hydrocarbons in cigarette smoke results in oxidative stress and the production of oxidized low-density lipoprotein (ox-LDL). ox-LDL accumulation in macrophages and smooth muscle-derived pro-inflammatory foam cells is a hallmark of atherosclerosis (21).

Studies using $\mathrm{AhR}^{-/}$mice have revealed that the $\mathrm{AhR}$ is a vital regulator of growth, development and material metabolism $(22,23)$. Recent reports revealed that the AhR may exert harmful effects relating to endothelial dysfunction and immune disorders $(24,25)$. AhR ligands activate the inflammatory axis in vascular endothelial cells to promote cell apoptosis and the inflammatory response (26).

The aim of the present review was to discuss the nature of the AhR, mediation of exogenous drugs, and potential targets for modification of cardiovascular genes. The role of the AhR receptor in the cardiovascular system, particularly the mechanism of action of AhR in atherosclerosis, is discussed in the present review. The role of the AhR in the development of novel therapeutic agents for the treatment of cardiovascular diseases is also presented.

\section{AhR regulation in atherosclerosis pathogenesis}

Atherosclerosis is a chronic inflammatory disease $(27,28)$. The pathology of atherosclerosis can be summarized as follows. Foreign or endogenous substances, such as PAHs, PCBs and indoleamine 2,3-dioxygenase,cause oxidative stress, inflammation and the release of interleukin (IL) 1 and tumor necrosis factor (TNF) which stimulate chemokines, vascular endothelial cells, vascular endothelial cells, or neutrophils in the vascular interstitium $(29,30)$. Inflammatory factors induce the oxidation of low-density lipoproteins which are phagocytized by macrophages which subsequently become lipid lines (31). The inflammatory factors induce the chemotaxis of monocytes in blood vessels into the stromal cells, where they differentiate into macrophages $(32,33)$. This is the early development of atherosclerosis (34). Lipids (mainly cholesterol) are deposited in the intima of large and medium blood vessels $(35,36)$. Smooth muscle cells and collagen fibers increase in number, and, secondary to necrosis, atheromatous plaques form. The plaques often cause different degrees of stenosis of the vascular lumen (37). Diseases with hardening of the blood vessel wall may present with ischemic changes in the end organs.

AhR signaling pathway in inflammation and atherosclerosis. Atherosclerosis is an inflammatory immune disease; it's inflammatory etiology was first proposed by Ross (28). Nuclear factor $\kappa-\mathrm{B}(\mathrm{NF}-\kappa \mathrm{B})$ is a key signal transduction factor and plays a central role in inflammatory cytokine-mediated inflammatory responses. When cells are stimulated by various internal factors including SRC- 1 and p 300 , the NF- $\kappa$ B signaling pathway is activated, and nuclear factors combine with the corresponding genes, thereby regulating the expression of target genes that magnify the inflammatory response, such as chemokines, inflammatory cytokines (including TNF- $\alpha$, IL-1 and IL-6) and adhesion molecules [including intercellular cell adhesion molecule-1 and vascular cell adhesion molecule-1 (VCAM-1)] (29,38). In the cytoplasm, AhR competitively binds to the RELA proto-oncogene, NF- $\kappa \mathrm{B}$ subunit (RELA) in NF- $\kappa \mathrm{B}$ in a 'tethered' manner, preventing the AhR from combining with a required synergistic activator (39). By binding to the promoter of AhR-NF- $\kappa \mathrm{B} 1$, RELA regulates the promoter sequence, affecting the expression of the AhR (40). In the coronary endothelium, whether the AhR signaling pathway exerts adverse effects on physiological functions through the $\mathrm{NF}-\kappa \mathrm{B}$ signaling pathway remains unreported (41).

There are three hypotheses underlying the AhR signaling pathways that mediate inflammation and promote atherosclerosis. The first hypothesis involves the signaling of downstream inflammatory factors such as VCAM-1 via the AhR/NF- $\mathrm{B}$ signaling pathway, which leads to monocyte chemotaxis (42). Macrophages and monocytes are targeted by polycyclic aromatic hydrocarbons involved in the physiological and pathological processes of atherosclerosis (43). The second hypothesis postulates that the AhR promotes macrophages absorption of ox-LDL to form foam cells by mediating endogenous and exogenous ligands such as ox-LDL, lipopolysaccharides and TCDD. In vitro studies have revealed that cholesterol accumulation in foam cells caused by particulate matter-induced inflammation is an early sign of cardiovascular disease $(30,44)$. However, the inhibitory effect of AhR inhibitors on foam cells and inflammation have not been investigated. It is believed that these mechanisms will be elucidated by extensive research of the AhR. The third hypothesis involves the increased proliferation of vascular smooth muscle cells (VSMCs), which is a critical factor in the occurrence of vascular complications. Yisireyili et al (45) exposed VSMCs to indoxyl sulfate, an agonist of AhR. Indoxyl sulfate induces VSMC proliferation via the activation of the AhR, the $\mathrm{NF}-\kappa \mathrm{B}$ signaling pathway and reactive oxygen species (ROS) production (Fig. 3).

AhR signaling pathway in oxidative stress and atherosclerosis. AhR mediates exogenous chemicals, such as TCDD and dioxin-like planar polychlorinated biphenyls (PCBs), and 


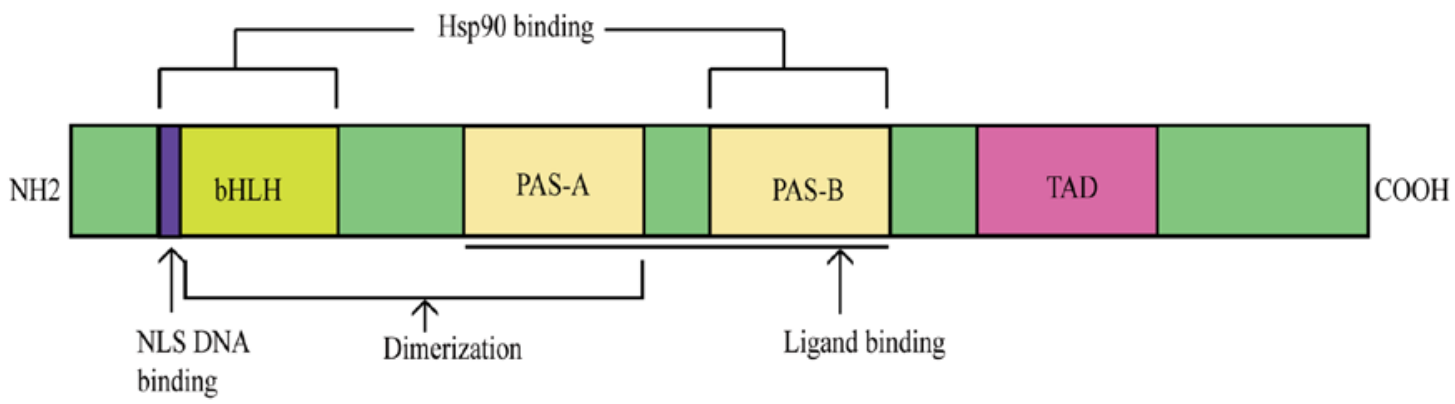

Figure 1. Structure of the AhR. The AhR consists of a bHLH/PAS domain and a TAD. AhR, aryl hydrocarbon receptor; bHLH, basic helix-loop-helix; PAS, PER-ARNT-SIM; TAD, transactivation domain; Hsp90, heat shock protein 90; NLS, nuclear localization sequence.

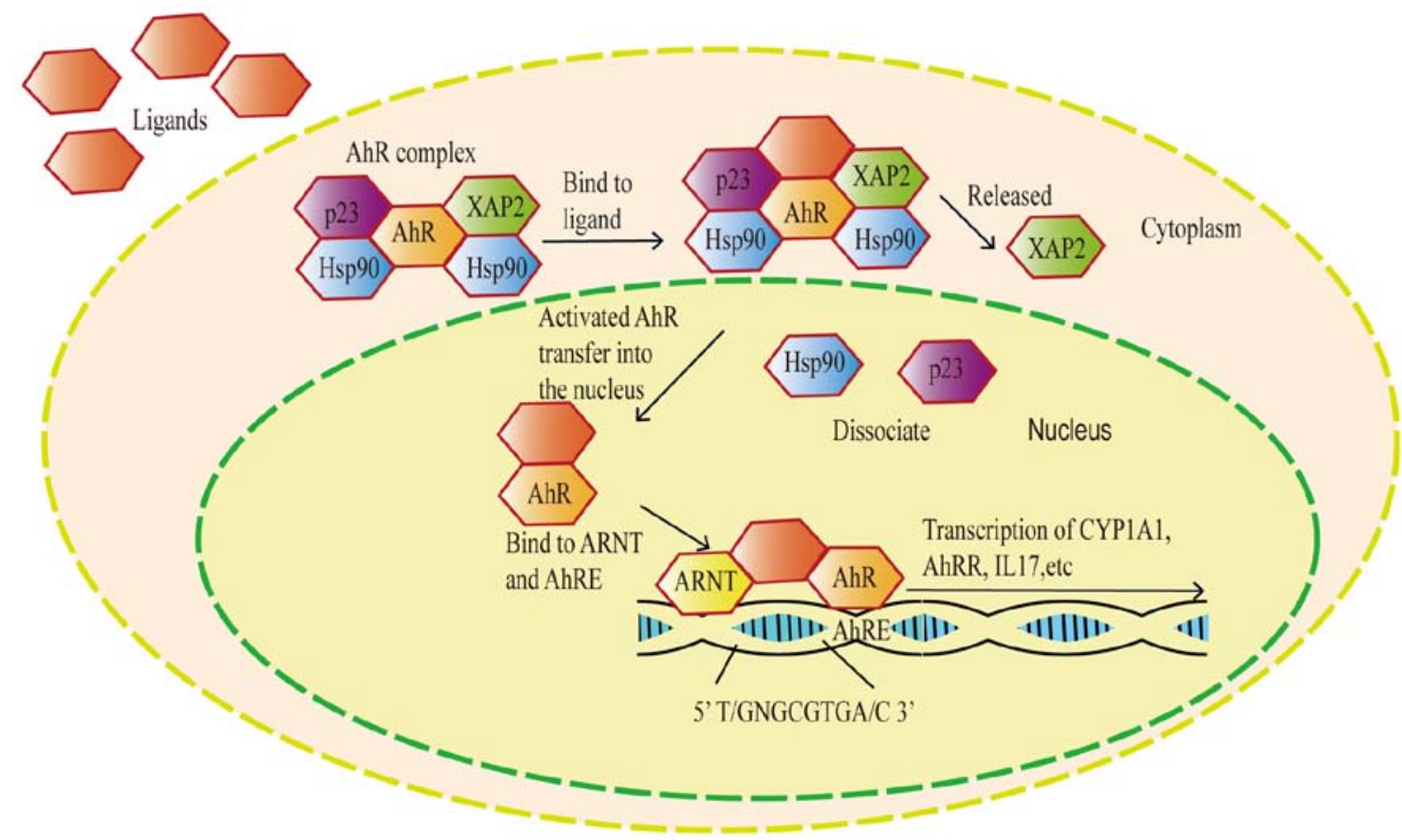

Figure 2. Model of the AhR signaling pathway. Upon binding to a ligand, the AhR is activated and enters the nucleus, where it binds to ARNT on AhRE and promotes transcription of downstream genes including CYP1A1 and IL-1. AhR, aryl hydrocarbon receptor; ARNT, aryl hydrocarbon receptor nuclear translocator; AhRE, aryl hydrocarbon response element; CYP1A1, cytochrome P450 family 1 subfamily A member 1; IL-1, interleukin 1; XAP2, aryl hydrocarbon receptor interacting protein; AHRR, aryl-hydrocarbon receptor repressor; IL-11, interleukin 17; Hsp90, heat shock protein 90; p23, prostaglandin E synthase 3.

endogenous substances, including indoxyl sulfate and arachidonic acid, by activating NADPH oxidase to produce ROS that directly damages vascular endothelial cells. This may result in a cellular oxidative stress/antioxidant imbalance that leads to cell damage and reduces the integrity of the vascular endothelium $(46,47)$. Previous studies have revealed that ROS mediate the transcription of specific genes, such as NF- $\kappa \mathrm{B}$, which mediate the transcription of inflammatory inducible nitric oxide synthase $(44,48)$.

AhR signaling pathway in lipid deposition and atherosclerosis. Lipid deposition is an essential external condition for foam cell formation (49). The current clinical treatment mainly relies on lipid-lowering drugs such as atorvastatin and fenofibrate (50). Lipid metabolism mainly occurs in the liver. It has been validated by recent studies that the AhR not only detoxifies, but also regulates lipid metabolism in the liver (51). Environmental pollutants such as TCDD and benzo(a)pyrene
(BP) inhibit the expression of NPC intracellular cholesterol transporter 1 in an AhR-dependent manner, promoting lipid deposition (52).

Lipid deposition can be induced by several AhR ligands. TCDD is a classical AhR ligand. A previous study revealed that $\alpha$-endosulfan and 2,3,7,8-TCDD jointly downregulate the expression of glucose- and lipid-associated genes in the liver, such as nuclear receptor subfamily 1 group $\mathrm{H}$ member 4 and nuclear receptor binding factor 2 (53). Lipoxin A4 (LXA4), an endogenous ligand of $\mathrm{AhR}$, is induced by homocysteine in patients with hyperhomocysteinemia. LXA4 promotes the binding of the AhR to the promoter of CD36 in hepatocytes and promotes CD36 expression, which increases the uptake of fatty acids and lipid accumulation by hepatocytes (54). Previous studies revealed that AhR activation affects the systemic metabolic functions of mice, including suppressed tricarboxylic acid cycle, disrupted lipid metabolism, amino acids metabolism, glycogenolysis, gluconeogenesis, thereby 


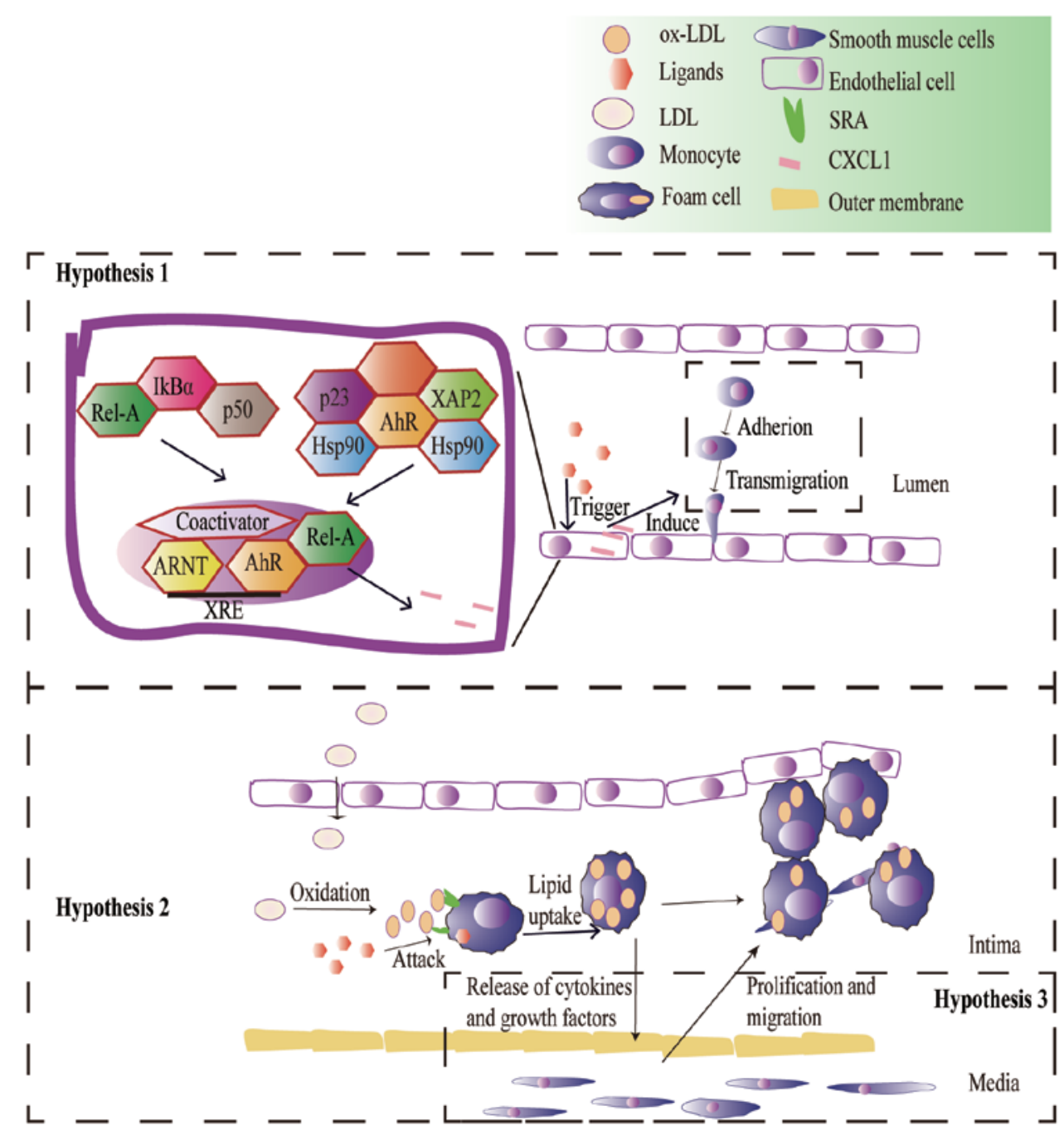

Figure 3. Role of AhR in the pathology of atherosclerosis. Hypothesis 1: Signaling of downstream inflammatory factors such as vascular cell adhesion molecule 1 via the AhR/nuclear factor- $\mathrm{kB}$ signaling pathway leads to monocyte chemotaxis. Hypothesis 2: AhR promotes macrophage absorption of ox-LDL and the formation of foam cells by mediating endogenous and exogenous ligands such as ox-LDL, lipopolysaccharide and 2,3,7,8-tetrachlorodibenzo-p-dioxin. Hypothesis 3: Increased proliferation of vascular smooth muscle cells is implicated in the occurrence of vascular complications. AhR, aryl hydrocarbon receptor; attack, pathological response induced by ligands; ox-LDL, oxidized low-density lipoprotein; p50, Rho guanine nucleotide exchange factor 7; RELA,

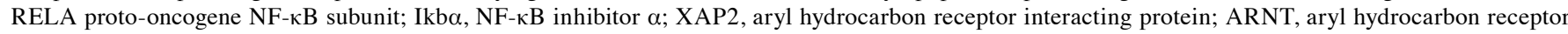
nuclear translocator; Hsp90, heat shock protein 90; p23, prostaglandin E synthase 3; CXCL1, C-X-C motif chemokine ligand 1; XRE, xenobiotic response element; SRA, scavenger receptor A.

increased hepatic lipogenesis, and promotedinflammatory signaling pathways $(23,55,56)$.

AhR knockout mice are widely used to study the role of the AhR in physiological functions. Activation of AhR protects against fatty liver induced by insulin resistance by activating fibroblast growth factor 21 (FGF21) to regulate lipid and energy metabolism in such mice (57). AhR knockout mice have increased levels of energy metabolism compared with normal mice, which protects against insulin resistance, hepatic steatosis, obesity and inflammation caused by a high-fat diet (HFD) (23). By contrast, the AhR protects against hepatic steatosis induced by a HFD and subsequent lipotoxicity. The AhR protects against fatty liver induced by insulin resistance by activating FGF21. The endocrine signaling pathway of AhR and FGF21 suggests that AhR is a crucial environmental modifier that combines signals from chemical exposure to regulate lipid and energy metabolism (57). In vivo experiments have revealed that locked nucleic acid 29, an inhibitor of microRNA (miR)-29, inhibits lipid deposition in the liver, and whole-genome analysis demonstrated increased AhR and sirtuin1 expression (58). AhR is a direct target gene of miR-29. Therefore, it may be an alternative therapeutic target for treating metabolic disorders such as dyslipidemia (58). PCB 153, mediated by AhR, can be considered as a 'secondary strike' mechanism for obesity/non-alcoholic fatty liver disease in the context of a HFD (59).

\section{Clinical research about $\mathrm{AhR}$ and atherosclerosis- associated diseases}

Studies investigating the association of the AhR signaling pathway and its downstream genes, glutathione S-transferase $\mu 1$ 


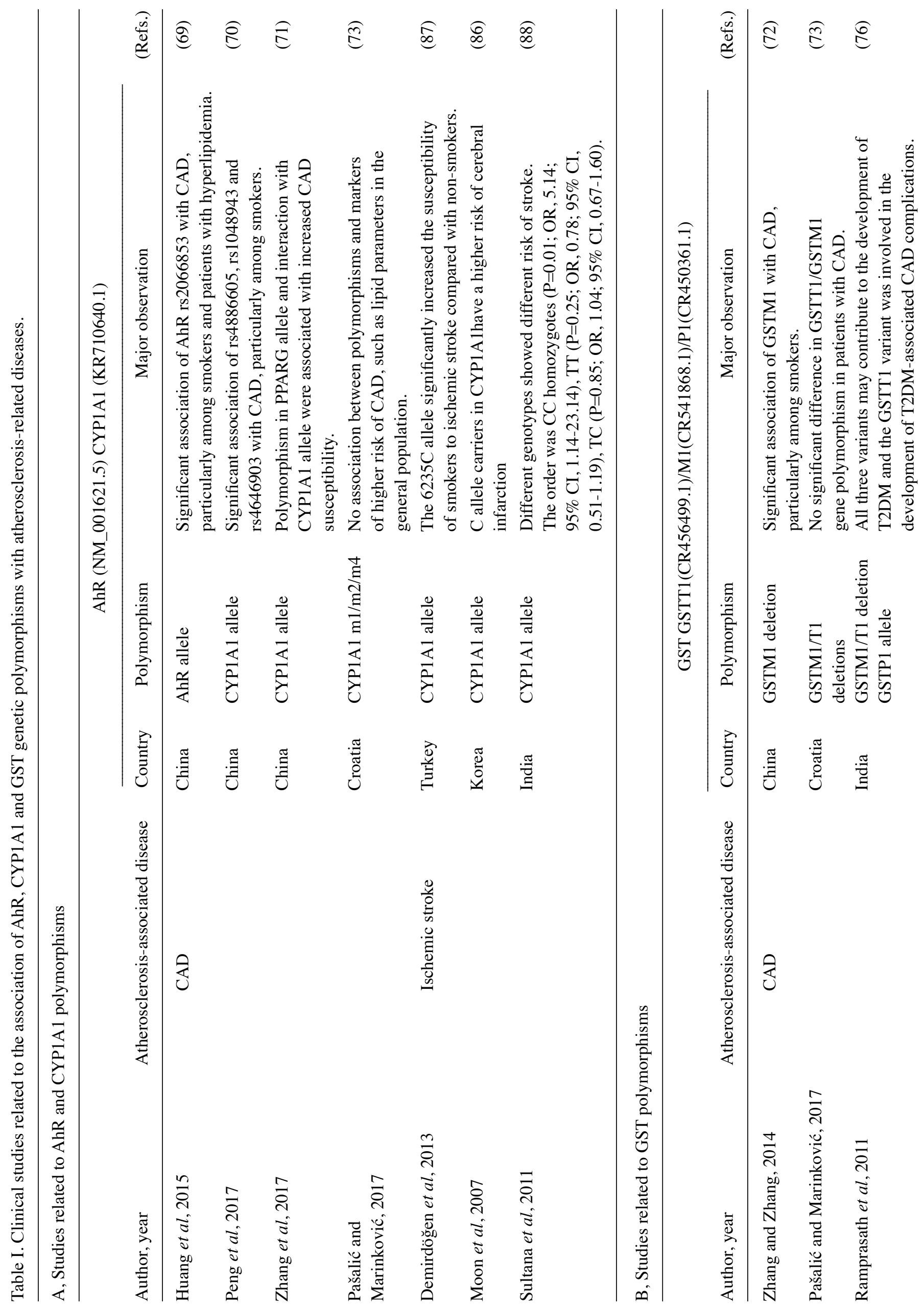




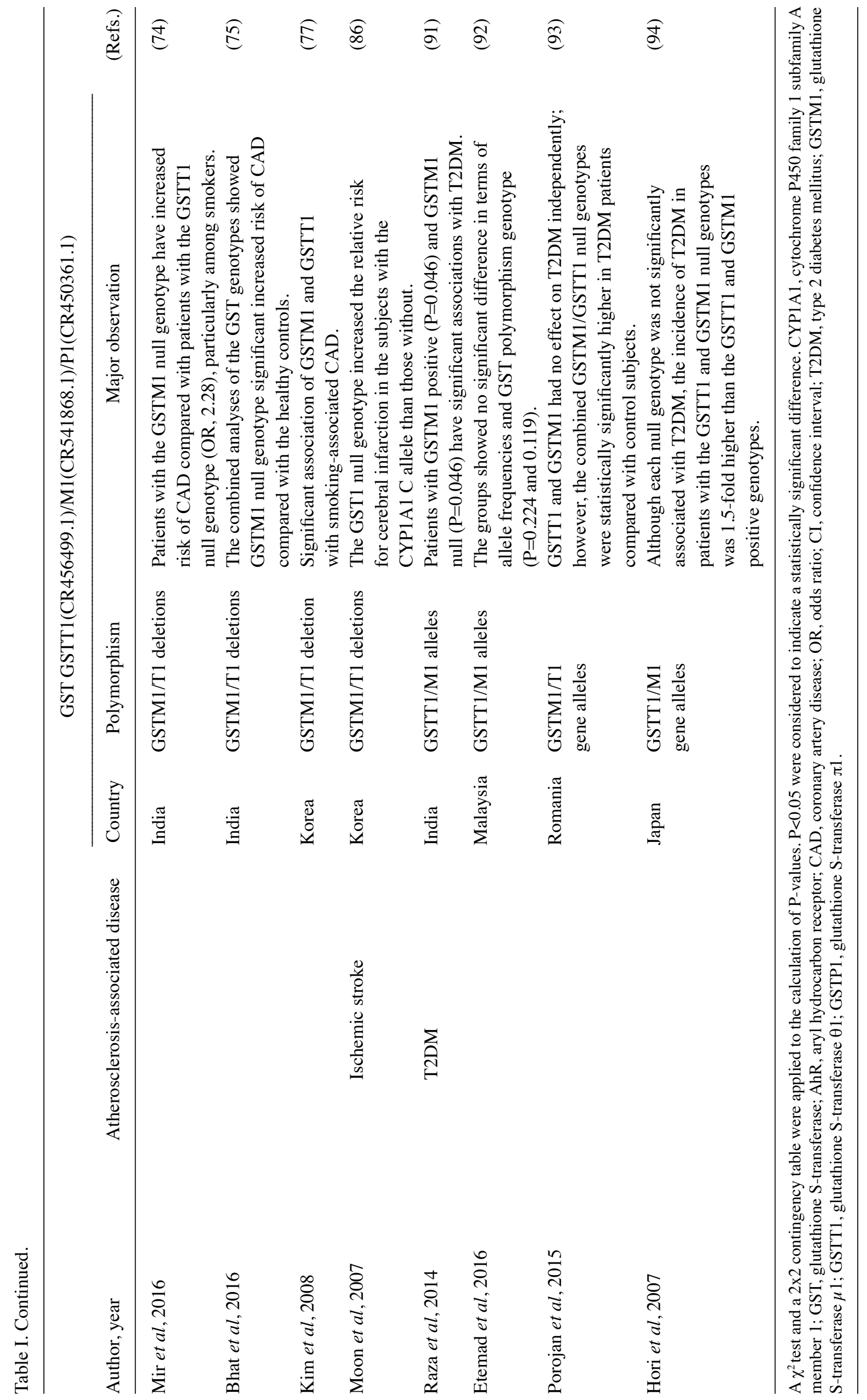




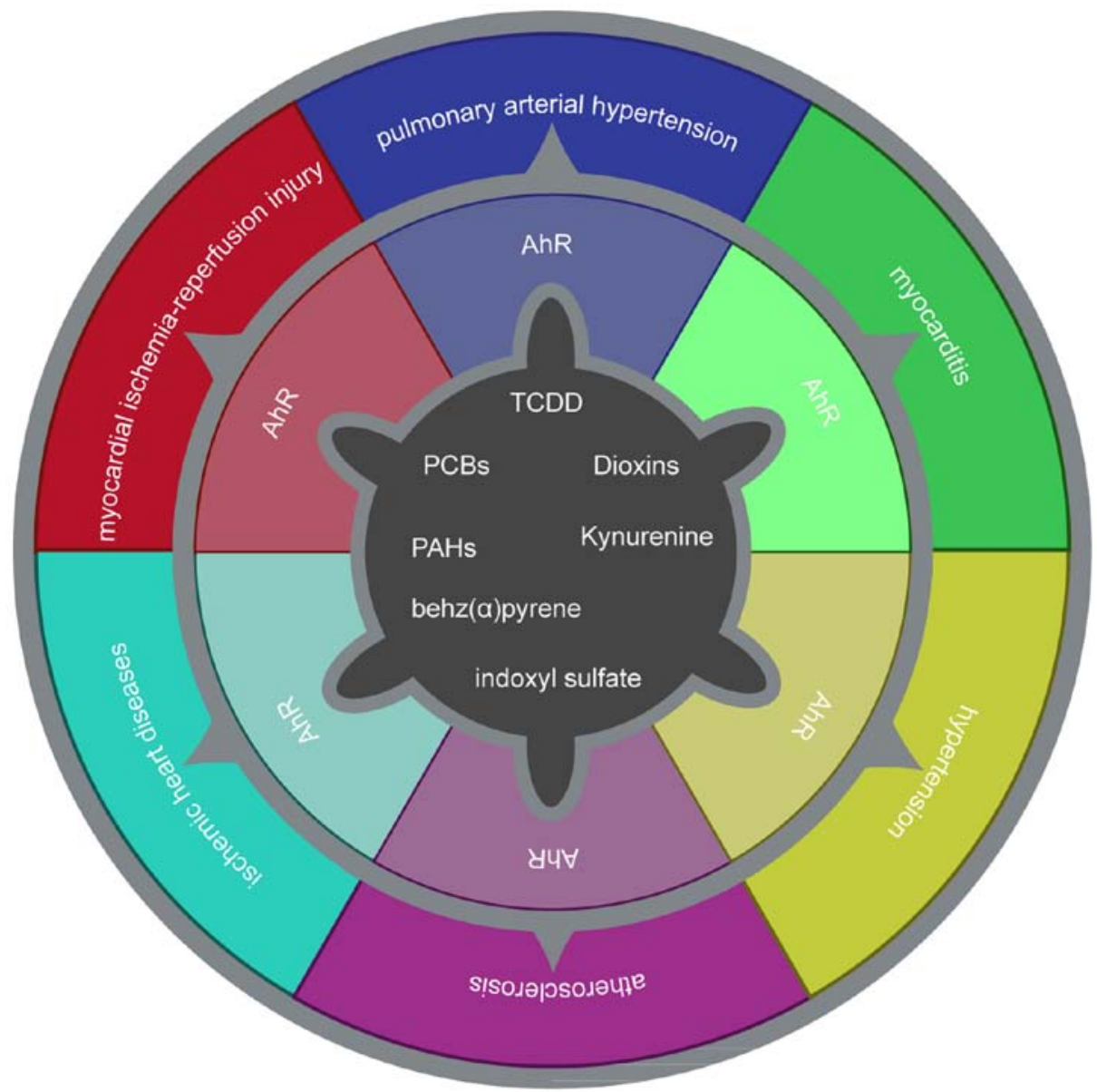

Figure 4. Relationship between AhR and cardiovascular disease.

(GSTM1) and glutathione S-transferase $\theta 1$ (GSTT1), with the risk and complications of atherosclerosis-associated diseases have yielded inconclusive results $(60,61)$. Recent studies revealed that AhR may be associated with atherosclerosis-associated diseases, including coronary artery disease (CAD), ischemic stroke and type 2 diabetes mellitus (T2DM) (62-64) (Table I). The current review presents clinical research to reveal their association.

Role of the AhR in the occurrence and development of CAD. CAD may result in mortality and is associated with atherosclerosis and thrombosis (65). There is no clinically relevant research on $\mathrm{AhR}$ gene polymorphisms and atherosclerosis, to the best of our knowledge, and few studies on AhR gene polymorphism and CAD (66-68). Receiver operating characteristic analysis of 939 patients with confirmed CAD and 868 normal subjects indicated that the AhR is a potential marker for objective measurement and evaluation of CAD in addition to other cardiac markers, such as creatine kinase-MB (69). Genotype frequencies of AhR rs2066853 reveal significant differences between CAD and control subjects, and hyperlipidemia and smoking significantly increased the risk of CAD associated with AhR polymorphism (69). Furthermore, the four subtypes of CAD with varying severity show significant differences in the distribution of AhR variants (70). Previous studies have investigated the association of CAD and the downstream mediators of the AhR signaling pathway, CYP1A1, GSTT1 and GSTM1, that mediate the metabolism of allogenic toxic substances (Table I). Previous studies in China have demonstrated significant associations of CYP1A1, GSTM1, GSTT1 and peroxisome proliferator activated receptor $\gamma$ with CAD, particularly in smokers (70-72).

A cross-sectional study in Croatia included 252 adult subjects with suspected exposure to PAHs; it was revealed that CYP1A1, GSTM1 and GSTT1 gene polymorphisms had no association with the risk of CAD (73).

Previous studies in India have demonstrated an association between GSTM1/GSTT1/glutathione S-transferase $\pi 1$ (GSTP1) polymorphism, coronary heart disease and blood lipid parameters (74-76). These findings suggest that blood lipid parameters in patients with coronary angiography are significantly associated with GSTM1/T1/P1 genotype distribution and GSTT1 deletion polymorphisms. However, a case-control study in the Republic of Korea revealed that GSTM1/T1 had no effect on the degree of lumen stenosis in CAD (77). Smokers carrying a GSTM1/T1 mutation have a higher risk of CAD (77).

Regarding the association between genetic polymorphisms of GSTM1 and smoking-related CAD, smokers with the GSTM1 null genotype have a greater risk of CAD compared with non-smokers with the GSTM1-positive genotype [odds ratio (OR), 2.07; 95\% confidence interval (CI), 1.06-4.07]. The association between genetic polymorphisms of GSTT1 and smoking related-CAD smoking shares the same tendency as that for GSTM1 (OR, 2.00; 95\% CI, 1.05-3.84). The 
association between GSTM1 and GSTT1 null genotypes in smoking-related CAD was also augmented when genetic polymorphisms of GSTM1 and GSTT1 were considered simultaneously (OR, 2.76; 95\% CI, 1.17-6.52) (77). On the basis of several epidemiological studies, AhR downstream genes are significantly associated with CAD, particularly in smokers with the GSTT1/M1 knockout gene (78-80).

AhR mRNA and the mRNA level of its allele are higher in the peripheral blood of patients with CAD compared with controls (69). Smoking increases the risk of CAD in patients with AhR gene polymorphisms. This may be due to the aromatic hydrocarbons present in smoke which cause lipid metabolism through the AhR signaling pathway (81). Furthermore, nicotine exposure induces VCAM-1, matrix metalloprotein (MMP)-2 and MMP-9 production in VSMCs and macrophages (82) and promotes vascular oxidative stress, leading to vascular damage (83).

AhR expression and polymorphisms are associated with the risk of ischemic stroke. Ischemic stroke is regarded as a potentially fatal disease (84) that occurs when there is a sudden decrease of blood supply to brain tissue, resulting in ischemia and hypoxia. Although cerebral and myocardial infarctions have different sites, the pathological mechanism is atherosclerosis (85). Therefore, cerebral infarction may be associated with vascular inflammation and oxidative stress; AhR downstream genes, such as CYP1A1, GSTT1 and GSTM1, may serve important roles in the pathogenesis (86) (Table I).

A case-control study in Turkey, which included 226 patients with ischemic stroke and 113 controls, showed significant differences between $6235 \mathrm{C}$ allele and the risk of ischemic stroke, particularly in smokers and patients with hypertension (87).

Moon et al (86) investigated 353 patients with cerebral infarction and 376 controls. A significantly larger number of patients with cerebral infarction had the CYP1A1 gene 3'-flanking region (T6235C) compared with the controls $(\mathrm{P}=0.017$; OR, 1.44; 95\% CI, 1.07-1.94). Analysis of gene-gene interactions showed that the GSTM1 null genotype increased the cerebral infarction risk in carriers of the CYP1A1 C allele $(\mathrm{P}=0.015$; OR, 1.47; 95\% CI, 1.08-2.00) (86).

To investigate the association between stroke and polymorphism of the CYP1A1 gene, Sultana et al (88) selected 215 patients with ischemic stroke and 162 age-matched controls. The results indicated that ischemic stroke had a significant association with the CYP1A1 genotype 'CC' $(\mathrm{P}=0.01$; OR, 5.14; 95\% CI, 1.14-23.14) in south Indian population, whereas Zhang et al (89) showed that CYP1A1 decreased the risk of disease in the eastern Han of China, and this contradiction showed CYP1A1 gene to display distinct alleles distribution among populations. In conclusion, CYP1A1 was shown to be significantly associated with ischemic stroke in certain clinical studies; however, further investigation is required to verify this association.

Association of AhR and its downstream genes with T2DM. T2DM, a metabolic disease, is associated with oxidative stress and chronic inflammation in adipose tissue (90). Previous epidemiological studies have revealed associations between oxidative stress-associated enzymes, such as GSTT1 and GSTM1, and diabetes (Table I). GSTT1 and GSTM1 are AhR downstream genes.
A case-control study in India revealed that GSTM1 and GSTT1 are associated with gene polymorphism-associated fat mass and obesity. GSTM1-positive and GSTM1 null genotypes had significant associations with T2DM, but there was no significant association with FTO $\alpha$-ketoglutarate-dependent dioxygenase polymorphism (91). Other epidemiological studies revealed that GSTM1 and GSTT1 did not have significant effects on T2DM $(92,93)$. Hori et al (94) did not reveal a significant association between T2DM and GSTT1/ M1 gene alleles, but the incidence rate of T2DM in GSTT1 and GSTM1 null genotypes was 1.5-fold higher than that in GSTM1 and GSTT1 positive genotypes. The aforementioned clinical studies demonstrated that GSTT1/M1 and diabetes are not highly associated and that further investigation is required to determine their associations.

\section{Conclusion}

The current review presented the association between the AhR and inflammation, oxidative stress, lipid infiltration and atherosclerosis. The AhR is closely associated with cardiovascular disease in terms of cardiac function, vascular development and blood pressure regulation (Fig. 4). In certain atherosclerosis-associated diseases, the AhR may serve a role as an oxidative stress signal transmitter. The AhR may be a potential target for the clinical treatment of cardiovascular disease. However, some important questions remain unanswered. The regulation of the AhR at the gene level has not been elucidated in humans. There are currently no drugs targeting the AhR in the clinic. The AhR is associated with other signaling pathways, including the Wnt and E2 factor signaling pathways, and further basic experiments are required to elucidate the roles of the AhR. The identification of novel endogenous ligands and the application of AhR knockout mice may clarify the role, regulation and intervention of the AhR in the treatment of atherosclerosis.

\section{Acknowledgements}

Not applicable.

\section{Funding}

The present study was supported by the National Natural Science Foundation of China (grant nos. 81700269 and 81741129), the Collaborative Innovation and Platform Environment Construction Projects of Guangdong Province (grant no. 2015A050502049) and the Characteristic Innovation Project of Department of Education of Guangdong Province (grant no. 2016KTSCX048).

\section{Availability of data and materials}

Not applicable.

\section{Authors' contributions}

WL and JZ conceived and designed the review. KZ retrieved the relevant literature and wrote the manuscript. TY provided a figure. QM, ZZ and YH reviewed and edited the manuscript. 


\section{Ethics approval and consent to participate}

Not applicable.

\section{Patient consent for publication}

Not applicable.

\section{Competing interests}

The authors declare that they have no competing interests.

\section{References}

1. Conney AH, Miller EC and Miller JA: The metabolism of methylated aminoazo dyes v. evidence for induction of enzyme synthesis in the rat by 3-methylcholanthre. Cancer Res 16 : 450-459, 1956.

2. Hu B, Huang H, Wei Q, Ren M, Mburu DK, Tian X and Su J: Transcription factors $\mathrm{CncC} / \mathrm{Maf}$ and AhR/ARNT coordinately regulate the expression of multiple GSTs conferring resistance to chlorpyrifos and cypermethrin in spodoptera exigua. Pest Manag Sci 75: 2009-2019, 2019.

3. Higgins LG and Hayes JD: Mechanisms of induction of cytosolic and microsomal glutathione transferase (GST) genes by xenobiotics and pro-inflammatory agents. Drug Metab Rev 43: 92-137, 2011.

4. De Anna JS, Leggieri LR, Arias Darraz L, Cárcamo JG, Venturino A and Luquet CM: Effects of sequential exposure to water accommodated fraction of crude oil and chlorpyrifos on molecular and biochemical biomarkers in rainbow trout. Comp Biochem Physiol C Toxicol Pharmacol 212: 47-55, 2018.

5. Davisson MT: Rules and guidelines for genetic nomenclature in mice: Excerpted version. Transgenic Res 6: 309-319, 1997.

6. Baricza E, Tamási V, Marton N, Buzás EI and Nagy G: The emerging role of aryl hydrocarbon receptor in the activation and differentiation of Th17 cells. Cell Mol Life Sci 73: 95-117, 2016.

7. Schmidt JV and Bradfield CA: Ah receptor signaling pathways. Annu Rev Cell Dev Biol 12: 55-89, 1996.

8. Go RE, Hwang KA and Choi KC: Cytochrome P450 1 family and cancers. J Steroid Biochem Mol Biol 147: 24-30, 2015.

9. Zhang N: The role of endogenous aryl hydrocarbon receptor signaling in cardiovascular physiology. J Cardiovasc Dis Res 2: 91-95, 2011.

10. Curran CP, Altenhofen E, Ashworth A, Brown A, Kamau-Cheggeh C, Curran M, Evans A, Floyd R, Fowler J, Garber H, et al: Ahr ${ }^{\mathrm{d}} \mathrm{Cypla} 2(-/-)$ mice show increased susceptibility to PCB-induced developmental neurotoxicity. Neurotoxicology 33 1436-1442, 2012

11. Bock KW: From TCDD-mediated toxicity to searches of physiologic AHR functions. Biochem Pharmacol 155: 419-424, 2018.

12. Tian Y, Rabson AB and Gallo MA: Ah receptor and NF- $\kappa B$ interactions: Mechanisms and physiological implications. Chem Biol Interact 141: 97-115, 2002.

13. Stejskalova L, Dvorak Z and Pavek P: Endogenous and exogenous ligands of aryl hydrocarbon receptor: Current state of art Curr Drug Metab 12: 198-212, 2011.

14. Lamas B, Natividad JM and Sokol H: Aryl hydrocarbon receptor and intestinal immunity. Mucosal Immunol 11: 1024-1038, 2018.

15. Wakamatsu T, Yamamoto S, Ito T, Sato Y, Matsuo K, Takahashi Y Kaneko Y, Goto S, Kazama JJ, Gejyo F and Narita I: Indoxyl sulfate promotes macrophage IL-1 $\beta$ production by activating aryl hydrocarbon receptor/NF- $/$ /MAPK cascades, but the NLRP3 inflammasome was not activated. Toxins (Basel) 10: E124, 2018

16. Nishiumi S, Yamamoto N, Kodoi R, Fukuda I, Yoshida K and Ashida $\mathrm{H}$ : Antagonistic and agonistic effects of indigoids on the transformation of an aryl hydrocarbon receptor. Arch Biochem Biophys 470: 187-199, 2008.

17. Peter Guengerich F, Martin MV, McCormick WA, Nguyen LP, Glover E and Bradfield CA: Aryl hydrocarbon receptor response to indigoids in vitro and in vivo. Arch Biochem Biophys 423: 309-316, 2004

18. Li W, Li Y, Sun R, Zhou S, Li M, Feng M and Xie Y: Dual character of flavonoids in attenuating and aggravating ischemia-reperfusion-induced myocardial injury. Exp Ther Med 14: $1307-1314,2017$
19. Hubbard TD, Murray IA and Perdew GH: Indole and tryptophan metabolism: Endogenous and dietary routes to Ah Receptor activation. Drug Metab Dispos 43: 1522-1535, 2015.

20. Kewley RJ, Whitelaw ML and Chapman-Smith A: The mammalian basic helix-loop-helix/PAS family of transcriptional regulators. Int J Biochem Cell Biol 36: 189-204, 2004.

21. Bock KW: Human AHR functions in vascular tissue: Pro- and anti-inflammatory responses of AHR agonists in atherosclerosis. Biochem Pharmacol 159: 116-120, 2019.

22. Schmidt JV, Su GH, Reddy JK, Simon MC and Bradfield CA: Characterization of a murine ahR null allele: Involvement of the Ah receptor in hepatic growth and development. Proc Natl Acad Sci USA 93: 6731-6736, 1996.

23. Xu CX, Wang C, Zhang ZM, Jaeger CD, Krager SL, Bottum KM, Liu J, Liao DF and Tischkau SA: Aryl hydrocarbon receptor deficiency protects mice from diet-induced adiposity and metabolic disorders through increased energy expenditure. Int J Obes (Lond) 39: 1300-1309, 2015.

24. Gutiérrez-Vázquez C and Quintana FJ: Regulation of the immune response by the aryl hydrocarbon receptor. Immunity 48: 19-33, 2018.

25. Brinchmann BC, Skuland T Rambøl MH, Szoke K, Brinchmann JE, Gutleb AC, Moschini E, Kubátová A, Kukowski K, Le Ferrec E, et al: Lipophilic components of diesel exhaust particles induce Pro-inflammatory responses in human endothelial cells through AhR dependent pathway(s). Part Fibre Toxicol 15: 21, 2018.

26. Yu Y, Liu Q, Guo S, Zhang Q, Tang J, Liu G, Kong D, Li J, Yan S, Wang R, et al: 2,3,7,8-Tetrachlorodibenzo-p-dioxin promotes endothelial cell apoptosis through activation of EP3/p38MAPK/Bcl-2 pathway. J Cell Mol Med 21: 3540-3551, 2017.

27. Yan ZQ and Hansson GK: Innate immunity, macrophage activation, and atherosclerosis. Immunol Rev 219: 187-203, 2007.

28. Ross R: Atherosclerosis-an inflammatory disease. N Engl J Med 340: 115-126, 1999.

29. Vogel CF, Khan EM, Leung PS, Gershwin ME, Chang WL, Wu D, Haarmann-Stemmann T, Hoffmann A and Denison MS: Cross-talk between aryl hydrocarbon receptor and the inflammatory response: A role for nuclear factor- $\kappa$ B. J Biol Chem 289: 1866-1875, 2014

30. Vogel CF, Sciullo E, Wong P, Kuzmicky P, Kado N and Matsumura F: Induction of proinflammatory cytokines and C-reactive protein in human macrophage cell line U937 exposed to air pollution particulates. Environ Health Perspect 113: $1536-1541,2005$

31. Ledda A, González M, Gulfo J, Díaz Ludovico I, Ramella N, Toledo J, Garda H, Grasa M and Esteve M: Decreased OxLDL uptake and cholesterol efflux in THP1 cells elicited by cortisol and by cortisone through $11 \beta$-hydroxysteroid dehydrogenase type 1. Atherosclerosis 250: 84-94, 2016.

32. Huang Y, Du KL, Guo PY, Zhao RM, Wang B, Zhao XL and Zhang CQ: IL-16 regulates macrophage polarization as a target gene of mir-145-3p. Mol Immunol 107: 1-9, 2019.

33. Sieve I, Ricke-Hoch M, Kasten M, Battmer K, Stapel B, Falk CS, Leisegang MS, Haverich A Scherr M and Hilfiker-Kleiner D: A positive feedback loop between IL-1 $\beta$, LPS and NEU1 may promote atherosclerosis by enhancing a pro-inflammatory state in monocytes and macrophages. Vascul Pharmacol 103: 16-28, 2018.

34. Abdolmaleki F, Gheibi Hayat SM, Bianconi V, Johnston TP and Sahebkar A: Atherosclerosis and immunity: A perspective. Trends Cardiovasc Med 28: S1050-1738, 2018 (Epub ahead of print).

35. Ohtsuka M, Miyashita Y and Shirai K: Lipids deposited in human atheromatous lesions induce apoptosisof human vascular smooth muscle cells. J Atheroscler Thromb 13: 256-262, 2006.

36. Baumer Y, McCurdy S, Weatherby TM, Mehta NN, Halbherr S, Halbherr P, Yamazaki $N$ and Boisvert WA: Hyperlipidemia-induced cholesterol crystal production by endothelial cells promotes atherogenesis. Nat Commun 8: 1129, 2017

37. Barnes MJ and Farndale RW: Collagens and atherosclerosis. Exp Gerontol 34: 513-525, 1999.

38. Chitra P, Saiprasad G, Manikandan R and Sudhandiran G: Berberine inhibits smad and non-smad signaling cascades and enhances autophagy against pulmonary fibrosis. J Mol Med (Berl) 93: 1015-1031, 2015.

39. Ke S, Rabson AB, Germino JF, Gallo MA and Tian Y: Mechanism of suppression of cytochrome P-4501A1 expression by tumor necrosis Factor- $\alpha$ and lipopolysaccharide. J Biol Chem 276: 39638-39644, 2001. 
40. Aung HH, Lame MW, Gohil K, He G, Denison MS, Rutledge JC and Wilson DW: Comparative gene responses to collected ambient particles in vitro: Endothelial responses. Physiol Genomics 43: 917-929, 2011

41. Vogel CF and Matsumura F: A new cross-talk between the aryl hydrocarbon receptor and RelB, a member of theNF-kB family. Biochem Pharmacol 77: 734-745, 2009.

42. Vogel CF, Sciullo E, Li W, Wong P, Lazennec G and Matsumura F: RelB, a new partner of aryl hydrocarbon receptor-mediated transcription. Mol Endocrinol 21: 2941-2955, 2007.

43. Wang C, Petriello MC, Zhu B and Hennig B: PCB 126 induces monocyte/macrophage polarization and inflammation through ahR and NF- $\kappa$ B pathways. Toxicol Appl Pharmacol 367: 71-81, 2019.

44. Hennig B, Meerarani P, Slim R, Toborek M, Daugherty A, Silverstone AE and Robertson LW: Proinflammatory properties of coplanar PCBs: In vitro and in vivo evidence. Toxicol Appl Pharmacol 181: 174-183, 2002.

45. Yisireyili M, Saito S, Abudureyimu S, Adelibieke Y, Ng HY, Nishijima F, Takeshita K, Murohara T and Niwa T: Indoxy sulfate-induced activation of (Pro)renin receptor promotes cell proliferation and tissue factor expression in vascular smooth muscle cells. PLoS One 9: e109268, 2014.

46. Hennig B, Hammock BD, Slim R, Toborek M, Saraswathi V and Robertson LW: PCB-induced oxidative stress in endothelial cells: Modulation by nutritients. Int J Hyg Environ Health 205: 95-102, 2002.

47. Watanabe I, Tatebe J, Namba S, Koizumi M, Yamazaki J and Morita T: Activation of aryl hydrocarbon receptor mediates indoxyl sulfate-induced monocyte chemoattractant Protein-1 expression in human umbilical vein endothelial Cells. Circ J 77: 224-230, 2013.

48. Puga A, Barnes SJ, Chang C, Zhu H, Nephew KP, Khan SA and Shertzer HG: Activation of transcription factors activator protein-1 and nuclear factor- $\kappa \mathrm{B}$ by 2,3,7,8-tetrachlorodibenzo-p-dioxin. Biochem Pharmacol 59: 997-1005, 2000.

49. Chistiakov DA, Melnichenko AA, Myasoedova VA, Grechko AV and Orekhov AN: Mechanisms of foam cell formation in atherosclerosis. J Mol Med 95: 1153-1165, 2017.

50. Chan DC, Watts F, Ooi EM, Ji J, Johnson AG and Barrett PH: Atorvastatin and fenofibrate have comparable effects on VLDL-Apolipoprotein C-III kinetics in men with the metabolic syndrome. Arterioscler Thromb Vasc Biol 28: 1831-1837, 2008.

51. Mesnage R, Biserni M, Balu S, Frainay C, Poupin N, Jourdan F, Wozniak E, Xenakis T, Mein CA and Antoniou MN: Integrated transcriptomics and metabolomics reveal signatures of lipid metabolism dysregulation in hepaRG liver cells exposed to PCB 126. Arch Toxicol 92: 2533-2547, 2018.

52. Podechard N, Le Ferrec E, Rebillard A, Fardel O and Lecureur V: NPC1 repression contributes to lipid accumulation in human macrophages exposed to environmental aryl hydrocarbons. Cardiovasc Res 82: 361-370, 2009.

53. Ambolet-Camoit A, Ottolenghi C, Leblanc A, Kim MJ, Letourneur F, Jacques S, Cagnard N, Guguen-Guillouzo C, Barouki R and Aggerbeck M: Two persistent organic pollutants which act through different xenosensors (alpha-endosulfan and 2,3,7,8 tetrachlorodibenzo-p-dioxin) interact in a mixture and downregulate multiple genes involved in human hepatocyte lipid and glucose. Biochimie 116: 79-91, 2015.

54. Yao L, Wang C, Zhang X, Peng L, Liu W, Zhang X, Liu Y, He J, Jiang C, Ai D and Zhu Y: Hyperhomocysteinemia activates the aryl hydrocarbon receptor/CD36 pathway to promote hepatic steatosis in mice. Hepatology 64: 92-105, 2016.

55. Van Breda SGJ, Claessen SMH, van Herwijnen $M$, Theunissen DHJ, Jennen DGJ, de Kok TMCM and Kleinjans JCS: Integrative omics data analyses of repeated dose toxicity of valproic acid in vitro reveal new mechanisms of steatosis induction. Toxicology 393: 160-170, 2018.

56. Zhang L, Hatzakis E, Nichols RG, Hao R, Correll J, Smith PB, Chiaro CR, Perdew GH and Patterson AD: Metabolomics reveals that aryl hydrocarbon receptor activation by environmental chemicals induces systemic metabolic dysfunction in mice. Environ Sci Technol 49: 8067-8077, 2015.

57. Lu P, Yan J, Liu K, Garbacz WG, Wang P, Xu M, Ma X and Xie W: Activation of aryl hydrocarbon receptor dissociates fatty liver from insulin resistance by inducing FGF21. Hepatology 61: 1908-1919, 2015.

58. Kurtz CL, Fannin EE, Toth CL, Pearson DS, Vickers KC and Sethupathy P: Inhibition of miR-29 has a significant lipid-lowering benefit through suppression of lipogenic programs in liver. Sci Rep 5: 12911, 2015.
59. Wahlang B, Falkner KC, Gregory B, Ansert D, Young D, Conklin DJ, Bhatnagar A, McClain CJ and Cave M: Polychlorinated biphenyl 153 is a diet-dependent obesogen that worsens nonalcoholic fatty liver disease in male C57BL6/J mice. J Nutr Biochem 24: 1587-1595, 2013.

60. Han SG, Han SS, Toborek M and Hennig B: EGCG protects endothelial cells against PCB 126-induced inflammation through inhibition of AhR and induction of Nrf2-regulated genes. Toxicol Appl Pharmacol 261: 181-188, 2012.

61. Wang Z, Yang H, Ramesh A, Roberts LJ, Zhou L, Lin X, Zhao Y and Guo $\mathrm{Z}$ : Overexpression of $\mathrm{Cu} / \mathrm{Zn}$-superoxide dismutase and/or catalase accelerates benzo(a)pyrene detoxification by upregulation of the aryl hydrocarbon receptor in mouse endothelial cells. Free Radic Biol Med 47: 1221-1229, 2009.

62. Kim JB, Pjanic M, Nguyen T, Miller CL, Iyer D, Liu B, Wang T, Sazonova O, Carcamo-Orive I, Matic LP, et al: TCF21 and the environmental sensor aryl-hydrocarbon receptor cooperate to activate a pro-inflammatory gene expression program in coronary artery smooth muscle cells. PLoS Genet 13: e1006750, 2017.

63. Li X, Liu N, Wang Y, Liu J, Shi H, Qu Z, Du T, Guo B and Gu B: Brain and muscle aryl hydrocarbon receptor nuclear translocator-like protein-1 cooperates with glycogen synthase kinase- $3 \beta$ to regulate osteogenesis of bone-marrow mesenchymal stem cells in type 2 diabetes. Mol Cell Endocrinol 440: 93-105, 2016.

64. Wnuk A and Kajta M: Steroid and xenobiotic receptor signalling in apoptosis and autophagy of the nervous system. Int $\mathbf{J}$ Mol Sci 18: E2394, 2017

65. Benjamin EJ, Virani SS, Callaway CW, Chamberlain AM, Chang AR, Cheng S, Chiuve SE, Cushman M, Delling FN, Deo R, et al: American heart association council on epidemiology and prevention statistics committee and stroke statistics subcommittee: Heart disease and stroke statistics-2018 update: A report from the american heart association. Circulation 137: e67-e492, 2018.

66. Zou JG, Ma YT, Xie X, Yang YN, Pan S, Adi D, Liu F and Chen BD: The association between CYP1A1 genetic polymorphisms and coronary artery disease in the uygur and han of China. Lipids Health Dis 13: 145, 2014.

67. Taspinar M, Aydos S, Sakiragaoglu O, Duzen IV, Yalcinkaya A, Oztuna D, Bardakci H, Tutar E and Sunguroglu A: Impact of genetic variations of the CYP1A1, GSTT1, and GSTM1 genes on the risk of coronary artery disease. DNA Cell Biol 31: 211-218, 2012.

68. Manfredi S, Federici C, Picano E, Botto N, Rizza A and Andreassi MG: GSTM1, GSTT1 and CYP1A1 detoxification gene polymorphisms and susceptibility to smoking-related coronary artery disease: A case-only study. Mutat Res 621: 106-112, 2007.

69. Huang S, Shui X, He Y, Xue Y, Li J, Li G, Lei W and Chen C: AhR expression and polymorphisms are associated with risk of coronary arterial disease in Chinese population. Sci Rep 5: 8022, 2015.

70. Peng DD, Xie W and Yu ZX: Impact of interaction between CYP1A1 genetic polymorphisms and smoking on coronary artery disease in the han of China. Clin Exp Hypertens 39: 339-343, 2017.

71. Zhang X, Lv S, Guo C, Shi C, Chi Y, Zhao L, Wang G and Wang Z: Gene-gene interaction between PPARG and CYP1A1 gene on coronary artery disease in the Chinese han population. Oncotarget 8: 34398-34404, 2017.

72. Zhang ZX and Zhang Y: Glutathione S-transferase M1 (GSTM1) null genotype and coronary artery disease risk: A meta-analysis. Int J Clin Exp Med 7: 3378-3384, 2014.

73. Pašalić D and Marinković N: Genetic polymorphisms of the CYP1A1, GSTM1, and GSTT1 enzymes and their influence on cardiovascular risk and lipid profile in people who live near a natural gas plant. Arh Hig Rada Toksikol 68: 46-52, 2017.

74. Mir R, Bhat MA, Javaid J, Shah N, Kumar P, Sharma E, Jhu C, Basak S, Amle D, Ray PC, et al: Glutathione S-transferase M1 and T1 (rs4025935 and rs71748309) null genotypes are associated with increased susceptibility to coronary artery disease in Indian Populations. Acta Cardiol 71: 678-684, 2016.

75. Bhat MA and Gandhi G: Association of GSTT1 and GSTM1 gene polymorphisms with coronary artery disease in north Indian punjabi population: A case-control study. Postgrad Med J 92: 701-706, 2016.

76. Ramprasath T, Senthil Murugan P, Prabakaran AD, Gomathi P, Rathinavel A and Selvam GS: Potential risk modifications of GSTT1, GSTM1 and GSTP1 (glutathione-S-transferases) variants and their association to CAD in patients with type-2 diabetes. Biochem Biophys Res Commun 407: 49-53, 2011. 
77. Kim SJ, Kim MG, Kim KS, Song JS, Yim SV and Chung JH: Impact of glutathione s-transferase M1 and T1 gene polymorphisms on the smoking-related coronary artery disease. J Korean Med Sci 23: 365-372, 2008.

78. Manfredi S, Calvi D, del Fiandra M, Botto N, Biagini A and Andreassi MG: Glutathione S-transferase T1- and M1-null genotypes and coronary artery disease risk in patients with type 2 diabetes mellitus. Pharmacogenomics 10: 29-34, 2009.

79. Wang LS, Tang JJ, Tang NP, Wang MW, Yan JJ, Wang QM, Yang ZJ and Wang B: Association of GSTM1 and GSTT1 gene polymorphisms with coronary artery disease in relation to tobacco smoking. Clin Chem Lab Med 46: 1720-1725, 2008.

80. Masetti S, Botto N, Manfredi S, Colombo MG, Rizza A, Vassalle C, Clerico A, Biagini A and Andreassi MG: Interactive effect of the glutathione S-transferase genes and cigarette smoking on occurrence and severity of coronary artery risk. J Mol Med (Berl) 81: 488-494, 2003.

81. Kalpana C, Rajasekharan KN and Menon VP: Modulatory effects of curcumin and curcumin analog on circulatory lipid profiles during nicotine-induced toxicity in wistar rats. J Med Food 8: 246-250, 2005.

82. Li ZZ, Guo ZZ, Zhang Z, Cao QA, Zhu YJ, Yao HL, Wu LL and Dai QY: Nicotine-induced upregulation of VCAM-1, MMP-2, and MMP-9 through the $\alpha 7-n$ AChR-JNK pathway in RAW264.7 and MOVAS cells. Mol Cell Biochem 399: 49-58, 2015.

83. Abdel Fattah S, Rizk AAE, Motawie AG, Abd El-Galil TI and El Sebaie M: Effects of nicotine on rat adrenal gland: Crosstalk between oxidative and inflammatory markers, and amelioration by melatonin. Biotech Histochem 19: 1-10, 2018.

84. O'Donnel MJ, Chin SL, Rangarajan S, Xavier D, Liu L, Zhang H, Rao-Melacini P, Zhang X, Pais P, Agapary S, et al: Global and regional effects of potentially modifiable risk factors associated with acute stroke in 32 countries (INTERSTROKE): A case control study. Lancet 388: 761-775, 2016.

85. Zhu H, Li Z, Lv J and Zhao R: Effects of cerebral small vessel disease on the outcome of patients with ischemic stroke caused by large artery atherosclerosis. Neurol Res 40: 381-390, 2018.

86. Moon KS, Lee HJ, Hong SH, Kim HM and Um JY: CYP1A1 and GSTM1/T1 genetic variation in predicting risk for cerebral infarction. J Mol Neurosci 32: 155-159, 2007.
87. Demirdöğen BC, Adali AC, Bek S, Demirkaya S and Adali O: Cytochrome P4501A1 genotypes and smoking- and hypertension-related ischemic stroke risk. Hum Exp Toxicol 32: 483-491, 2013.

88. Sultana S, Kolla VK, Peddireddy V, Jeedigunta Y, Penagaluru PK, Joshi S, Penagaluru UR and Penagaluru PR: Association of cypla1 gene polymorphism with ischemic stroke in south Indian population. Transl Stroke Res 2: 26-32, 2011.

89. Zhang M, Wu JM, Zhang QS, Yan DW, Ren LJ and Li WP: The association of CYP1A1 genetic polymorphisms and additional gene-gene interaction with ischemic stroke in the eastern han of China. Neurol Sci 37: 1679-1684, 2016.

90. Sindhu S, Akhter N, Kochumon S, Thomas R, Wilson A, Shenouda S, Tuomilehto J and Ahmad R: Increased expression of the innate immune receptor TLR10 in obesity and Type-2 diabetes: Association with ROS-mediated oxidative stress. Cell Physiol Biochem 45: 575-590, 2018.

91. Raza ST, Abbas S, Ahmad A, Ahmed F, Zaidi Zh and Mahdi F: Association of glutathione-s-transferase (GSTM1 and GSTT1) and FTO gene polymorphisms with type 2 diabetes mellitus cases in northern India. Balkan J Med Genet 17: 47-54, 2014.

92. Etemad A, Vasudevan R, Aziz AF, Yusof AK, Khazaei S, Fawzi N, Jamalpour S, Arkani M, Mohammad NA and Ismail P: Analysis of selected glutathione S-transferase gene polymorphisms in malaysian type 2 diabetes mellitus patients with and without cardiovascular disease. Genet Mol Res 15: 2016.

93. Porojan MD, Bala C, Ilies R, Catana A,Popp RA and Dumitrascu DL: Combined glutathione $\mathrm{S}$ transferase M1/T1 null genotypes is associated with type 2 diabetes mellitus. Clujul Med 88: 159-163, 2015.

94. Hori M, Oniki K, Ueda K, Goto S, Mihara S, Marubayashi T and Nakagawa K: Combined glutathione S-transferase T1 and M1 positive genotypes afford protection against type 2 diabetes in japanese. Pharmacogenomics 8: 1307-1314, 2007.

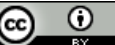

This work is licensed under a Creative Commons Attribution 4.0 International (CC BY 4.0) License. 